\title{
Thin-Layer Electroanalysis Microchip Reveals More about Electrochemical Reactions of Organic Compounds
}

\author{
Samuel J. Shin, ${ }^{\ddagger 1}$ Ji Yong Kim, ${ }^{\ddagger 1}$ Sohee An,,${ }^{1}$ Moonjoo Kim,,${ }^{1}$ Minjee Seo,${ }^{2}$ Su Yong Go, ${ }^{1}$ \\ Hyunho Chung, ${ }^{1}$ MinKeun Lee, ${ }^{1}$ Min-Gyeong Kim, ${ }^{3}$ Hong Geun Lee, ${ }^{1}$ Taek Dong Chung*1,4 \\ ${ }^{1}$ Department of Chemistry, Seoul National University, Seoul, 08826, Republic of Korea \\ ${ }^{2}$ Department of Chemistry Education, Korea National University of Education, Cheongju-si, Chungbuk 28173, \\ Republic of Korea \\ ${ }^{3}$ Department of Chemistry Education, Seoul National University, Seoul, 08826, Republic of Korea \\ ${ }^{4}$ Advanced Institutes of Convergence Technology, Suwon-si, Gyeonggi-do, 16229, Republic of Korea \\ \$These authors contributed equally.
}




\begin{abstract}
:
It is important but challenging to elucidate the electrochemical reaction mechanisms of organic compounds using electroanalytical methods. In this work, we exploited the advantages of classic thin-layer electrochemistry to develop a thin-layer electroanalysis microchip (TEAM). The TEAM provided better resolved voltammetric peaks than measurements under semi-infinite diffusion conditions. Importantly, because the analyte solution was mechanically isolated using a polyelectrolyte gel, rapid small-volume electrolysis allowed the accurate determination of the number of electrons transferred, $n$. The performance of the TEAM was validated using both voltammetry and coulometry of standard redox couples. Moreover, a spectroelectrochemical analysis of FM 1-43, an organic dye widely used in neuroscience, was successfully performed. Harnessing the analytical power of the TEAM, the electrochemical oxidation mechanisms of pivanilides and alkyltrifluoroborate salts were studied. Thus, the TEAM has the potential to provide invaluable mechanistic information and promote the rational design of electrosynthetic strategies.
\end{abstract}

KEY WORDS: thin-layer electrochemistry, thin-layer electroanalytical chip, electrochemical oxidation mechanism, number of electrons, voltammetry, coulometry, spectroelectrochemistry, FM 1-43, pivanilides, alkyltrifluoroborate salts, electroorganic chemistry 
Understanding the mechanisms of electrochemical reactions is important for rationally utilizing/producing molecules for use in the fields of energy/chemical conversion, ${ }^{1-4}$ bioelectrochemistry, ${ }^{5}$ and organic electrosynthesis. ${ }^{6-11}$ Such information is especially critical in electrosynthesis to improve yields or control reaction selectivity among competing pathways. Unlike homogenous reactions, heterogeneous electrochemical reactions are challenging to predict because electron transfer occurs at the solid/solution interface in the presence of a high electrolyte concentration. However, limited efforts have been made to develop suitable electrochemical techniques for elucidating reaction mechanisms. ${ }^{12-15}$ Cyclic voltammetry, which has been the most widely used technique, provides information of half wave potential, the number of voltammetric peaks, or relative peak currents. In addition, square wave voltammetry has recently gained attention for its ability to distinguish multi-electron transfer underneath an apparently single peak in specific cases. Nevertheless, generalization of these methods requires further improvements, especially to the resolution. ${ }^{16,17}$ A more intuitive and critical knowledge of reaction pathway is the number of electrons transferred per molecule in a heterogeneous redox reaction, $n$. However, most electrochemical methods ${ }^{18-21}$ that can provide $n$ are inappropriate for multistep reactions ${ }^{22}$ and nonaqueous systems. Although bulk electrolysis is a versatile and straightforward method without additional parameters and with fewer restrictions, it is time-consuming due to large solution volumes and often leads to overestimated results involving disproportionation or side reactions.

Thin-layer electrochemistry, which has been exploited to evaluate electrochemical parameters since the $1960 \mathrm{~s},{ }^{23-26}$ can address these issues if feasible in a small volume. In addition, it gives distinctive sharp and symmetrical voltammetric peaks without semi-infinite inbound mass transfer and thus can provides greater peak resolution. The differences between the thin-layer cell and semi-infinite diffusion measurements are demonstrated by digital simulation of the square wave voltammograms (SWVs) for two sequential electron transfers (Figure 1). As shown in Figure 1a, the two neighboring peaks are more distinguishable using the thin-layer cell than under semi-infinite diffusion conditions for the same $\Delta E^{0}$. This difference is due to a reduced mass transfer effect in the thin-layer cell, which leads to an earlier peak potential and a steeper current decrease with reactant depletion (Figure S1 and Video S1). Furthermore, SWVs as a function of frequency indicate that this peak separation is more evident at lower frequencies than at higher frequencies (Figure 1b). A low frequency and a small step potential are favorable for observing distinctive voltammetric behavior because a slower scanning is beneficial to achieve mass transfer equilibrium throughout the cell. Despite its usefulness, thin-layer electrochemistry has been impeded by lateral diffusion from the external solution and the absence of a standardized system.

(a)

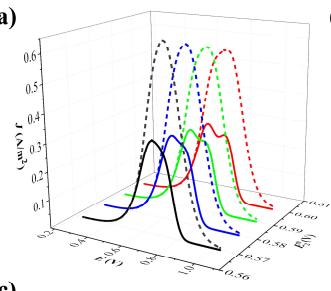

(c)

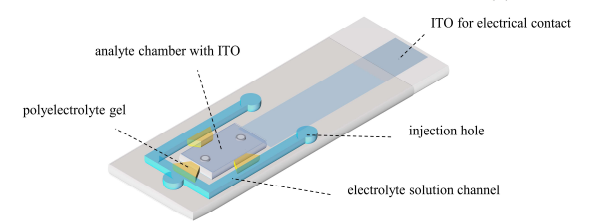

Figure 1. Simulated SWV curves of $20 \mu \mathrm{m}$ thin layer model (solid line) and semi-infinite diffusion model (dashed line) at different (a) $\Delta E^{0}$ and (b) frequency. Frequency was $15 \mathrm{~Hz}$ and $E_{2}{ }^{0}$ was $0.6 \mathrm{~V}$, respectively. (c) Schematic illustration of TEAM. 
By revisiting thin-layer electrochemistry, we devised a microchip device, the thin-layer electroanalysis microchip (TEAM), to extract information about electrochemical reaction mechanisms more effectively (Figure $1 \mathrm{c}$ and Scheme S1). The small height of $20 \mu \mathrm{m}$ allows immediate access of reactants to the electrode surface while also imparting the characteristic voltammetric features of thin-layer cells. Most importantly, lateral diffusion was prevented by mechanically confining the analyte solution to the working electrode using a polyelectrolyte gel salt bridge, thus enabling the accurate determination of $n$ via coulometry in a short time. For aqueous solutions, a polydiallyldimethylammonium chloride (pDADMAC) hydroge ${ }^{27}$ was constructed in the TEAM. For organic solvents, a lipophilic polyelectrolyte gel, polylaurylacrylate tetrakis[3,5-bis(trifluoromethyl)phenyl]borate (pLATFPB ${ }^{28,29}$ (Figure S2), was introduced by photopolymerization.

(a)

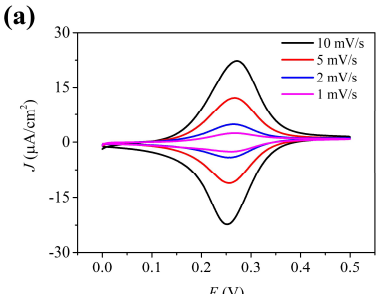

(c)

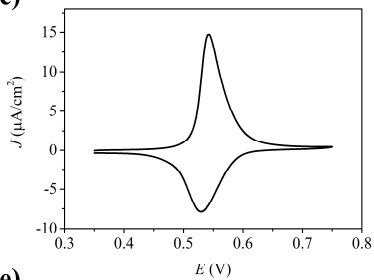

(e)

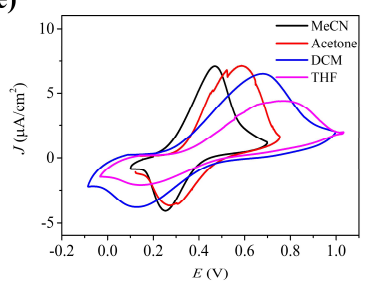

(b)

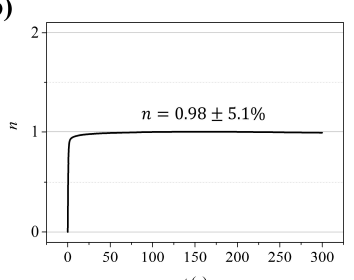

(d)

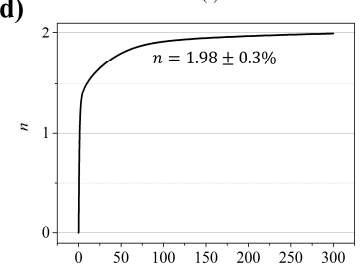

(f)

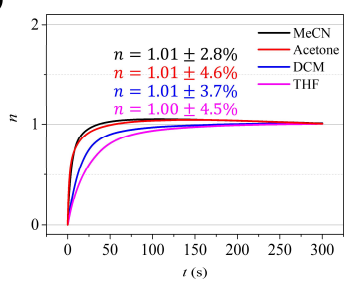

Figure 2. CVs and $n-t$ plot of standard redox species using TEAM. (a, b) CVs and $n-t$ plot $\left(E_{\text {app }}=0.4 \mathrm{~V}\right)$ of $2 \mathrm{mM}$ ferrocyanide in $1 \mathrm{M} \mathrm{KCl}$. (c) $\mathrm{CV}(2 \mathrm{mV} / \mathrm{s})$ and (d) $n-t$ plot $\left(E_{\text {app }}=0.7 \mathrm{~V}\right)$ of $1 \mathrm{mM}$ o-tolidine in $0.2 \mathrm{M}$ phosphate buffer (pH 2). (e) $\mathrm{CVs}$ $(10 \mathrm{mV} / \mathrm{s})$ and (f) $n-t$ plot of $1 \mathrm{mM}$ ferrocene in $0.1 \mathrm{M}$ TBAPF 6 MeCN $\left(E_{\text {app }}=0.5 \mathrm{~V}\right)$, acetone $\left(E_{\text {app }}=0.5 \mathrm{~V}\right)$, DCM $\left(E_{\text {app }}=0.7 \mathrm{~V}\right)$, and THF $\left(E_{\text {app }}=0.7 \mathrm{~V}\right)$ solution.

The validity of the TEAM as an electrochemical analytical device was investigated using the well-known redox species ferrocyanide, $o$-tolidine, and ferrocene $(\mathrm{Fc})$ (Figure 2). The cyclic voltammograms (CVs) of ferrocyanide exhibited very small peak-to-peak separations, ranging from $6 \mathrm{mV}$ at a scan rate of $1 \mathrm{mV} / \mathrm{s}$ to $19 \mathrm{mV}$ at a scan rate of $10 \mathrm{mV} / \mathrm{s}$ (Figure 2a and Table S1), as compared to $59 \mathrm{mV}$ for a reversible one-electron transfer reaction under semi-infinite diffusion conditions. In addition, the current returned to the baseline after the peak potential, leading to a symmetric peak shape. These characteristics are typical of thin-layer electrochemistry, as described above. As shown by the $n-t$ plot for ferrocyanide oxidation (Figure $2 \mathrm{~b}$ ), $n$ was measured accurately as 1 by successfully preventing lateral diffusion (Figure S3). The feasibility of the TEAM was further demonstrated using $o$-tolidine, which undergoes quasi-reversible two-electron oxidation under acidic conditions (Figure 2c and 2d) ${ }^{30,31}$ Similarly, a CV with a small $\Delta E_{\mathrm{p}}$ was observed, and constant potential electrolysis resulted in an $n$ value of 2, as expected. Finally, the TEAM was used to investigate $\mathrm{Fc}$ in various organic solvents, including acetonitrile $(\mathrm{MeCN})$, acetone, dichloromethane (DCM), and tetrahydrofuran (THF) (Figure 2e and 2f). The large peak-topeak potentials in the resulting CVs originates from the sluggish electron transfer kinetics in the organic solutions 
at the indium tin oxide (ITO) electrode (Figure S4) and the high resistances of the organic solutions and pLATFPB polyelectrolyte gel (Supporting Information). In addition, the variance in $E_{1 / 2}$ could be rationalized by the different reorganization energies of $\mathrm{Fc} / \mathrm{Fc}^{+}$in various solvents. ${ }^{32}$ Nevertheless, in all cases, $n$ values of 1 were obtained.

(a)

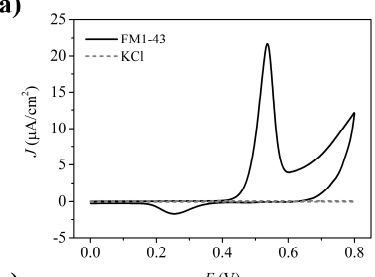

(c)

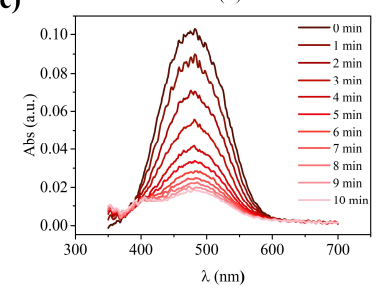

(b)

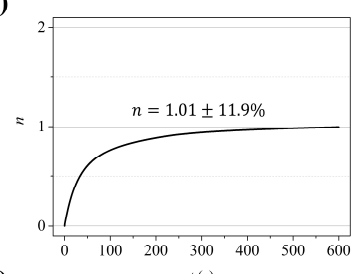

(d)

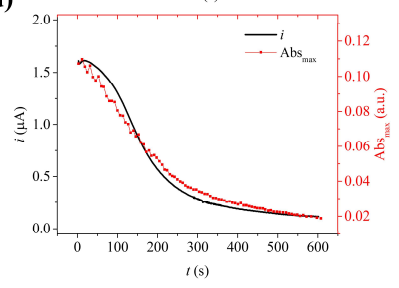

Figure 3. Electrochemical and spectroelectrochemical study of FM 1-43 using TEAM. (a) CV (5 mV/s) and (b) $n-t$ p lot $\left(E_{\text {app }}=0.5 \mathrm{~V}\right)$ of $2.5 \mathrm{mM} \mathrm{FM} 1-43$ in $1 \mathrm{M} \mathrm{KCl}$. (c) UV-VIS absorption spectrum obtained with simultaneou $\mathrm{s}$ electrolysis at $0.5 \mathrm{~V}$. (d) Co-plot of the maximum absorbance and current versus time.

Based on the validity of the TEAM, we applied it to the electrochemical analysis of less-explored organic compounds and investigated its feasibility for spectroelectrochemical measurements. One area that demands knowledge of the oxidation potential or $n$ of a molecule is neuroelectrochemistry for amperometric detection and quantitative analysis. Electrochemical investigations of FM 1-43, a fluorescent styryl dye used for visualizing exocytosis, ${ }^{33}$ are required to allow its application as a dual functional fluorescent and amperometric probe. The CV of FM 1-43 in the TEAM exhibited one sharp anodic peak with $E_{1 / 2}$ of $0.5 \mathrm{~V}$ followed by a broad anodic current (Figure 3a). The peaks observed using the TEAM were better defined than those obtained under semiinfinite diffusion conditions (Figure S5) as expected. The $n$ value determined for the first oxidation step was 1 (Figure 3b), suggesting the stoichiometry to count the number of FM 1-43 molecules from the amperometric peak at $0.5 \mathrm{~V}$ during exocytosis. Because of the transparency of the ITO electrode, the TEAM could be used as an in situ spectroelectrochemical cell with a path length of $20 \mu \mathrm{m}$. With FM 1-43, the maximum absorption peak at 480 $\mathrm{nm}$ gradually decreased and almost disappeared after electrolysis for $10 \mathrm{~min}$ (Figure 3c), indicating a structural change induced by one-electron oxidation. The decrease in the maximum absorbance with time was consistent with the trend observed for the current during electrolysis (Figure 3d), exemplifying the real-time monitoring of spectroelectrochemical properties. 


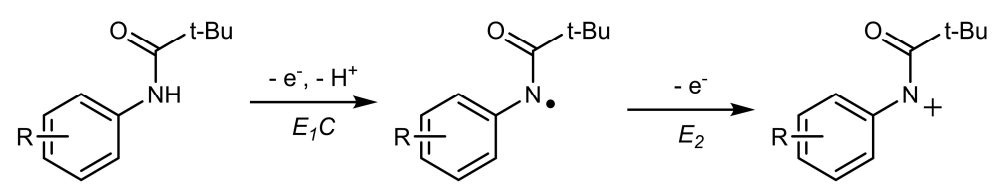

(a)

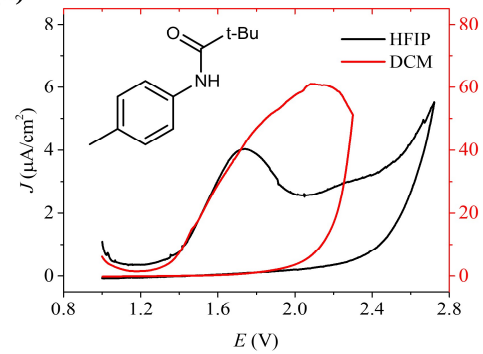

(d)

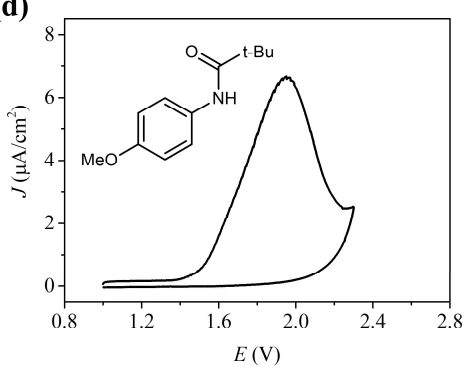

(b)

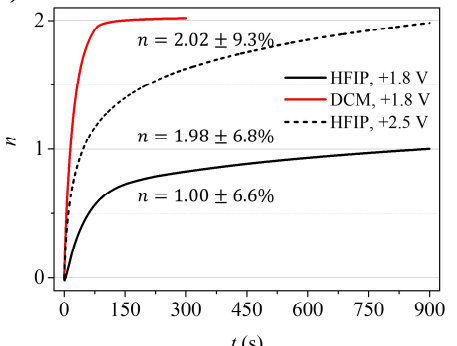

(e)

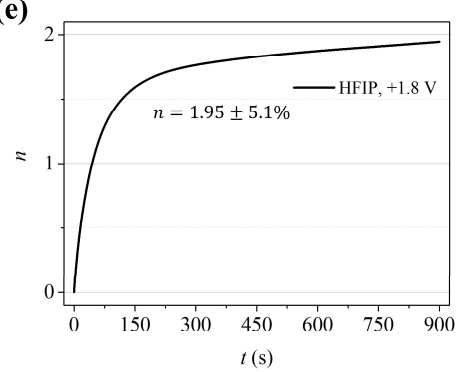

(c)

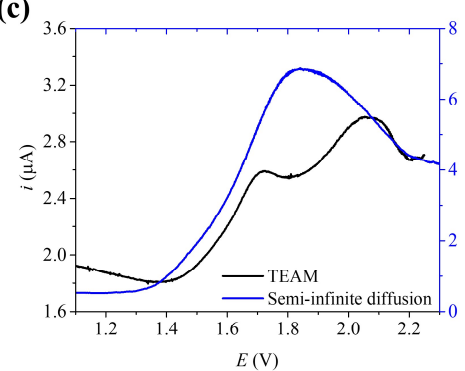

(f)

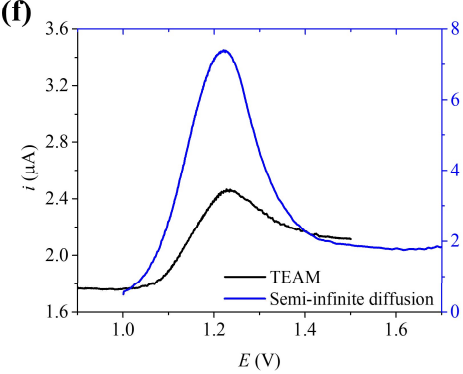

Figure 4. Electrochemical oxidation study of anilides using TEAM. (a) CVs $(10 \mathrm{mV} / \mathrm{s})$ and (b) $n-t$ plots $\left(E_{\text {app }}=1.8\right.$ a nd $2.5 \mathrm{~V}$ ) of $1 \mathrm{mM}$ 4-MePhNHPiv in $0.1 \mathrm{M} \mathrm{TBAPF}_{6}$ of HFIP and DCM solution. (c) SWVs with TEAM or semi-infinite diffusion condition of 4-MePhNHPiv in DCM. (d) $\mathrm{CV}(10 \mathrm{mV} / \mathrm{s})$, (e) $n-t$ plot $\left(E_{\text {app }}=1.8 \mathrm{~V}\right)$, and (f) SWVs with TEAM or semi-infinite diffusion condition of $1 \mathrm{mM}$ 4-MeOPhNHPiv in $0.1 \mathrm{M} \mathrm{TBAPF} 6$ of HFI $\mathrm{P}$ solution.

As a further demonstration of the applicability of the TEAM, we focused on elucidating the electrochemical reaction mechanisms of organic compounds in organic solvents. Anilide, an important building block in natural products and drugs, ${ }^{34-39}$ has been proposed to undergo electrochemical oxidation via an ECE mechanism partially unveiled by indirect evidence, including the number of peaks and oxidation potentials from voltammetry and product analysis from electrosynthesis of dianilide via $\mathrm{N}-\mathrm{N}$ bond formation. ${ }^{40}$ As accurate measurements of $n$ and distinguishable voltammetric peaks can provide a better understanding of the oxidation mechanism, electroanalyses were performed using the TEAM (Figure 4 and Figure S6). The voltammogram of $N-(p$ tolyl)pivalamide (4-MePhNHPiv) exhibited two distinct peaks in hexafluoroisopropanol (HFIP) (Figure 4a), with each peak corresponding to single-electron transfer (SET) (Figure 4b), in agreement with the previously suggested mechanism. ${ }^{40}$ For an anilide with a more electron-donating substituent, $N$-(4-methoxyphenyl)pivalamide (4MeOPhNHPiv), a voltammogram with a single peak was obtained (Figure 4d), corresponding to two-electron transfer (Figure 4e). Interestingly, the voltammogram of 4-MePhNHPiv in DCM showed a single peak corresponding to two-electron transfer. These observations were further confirmed by the SWV for both anilides (Figure $4 \mathrm{c}$ and $4 \mathrm{f}$ ). Owing to the superior resolution of SWV in the TEAM, two distinct peaks were obtained for 4-MePhNHPiv in DCM with a voltage difference of approximately $300 \mathrm{mV}$, whereas a single peak was observed under semi-infinite diffusion conditions. The overlap of the two oxidation potentials is presumably ascribable to poor stabilization of the radical intermediate by the solvent, which would promote facile two-electron transfer. Furthermore, in both $\mathrm{CV}$ and SWV measurements, the two oxidation peaks for 4-MeOPhNHPiv in HFIP 
overlapped because the cation formed during the second oxidation process could be stabilized by resonance, similar to quinone imine-like structures. ${ }^{40}$

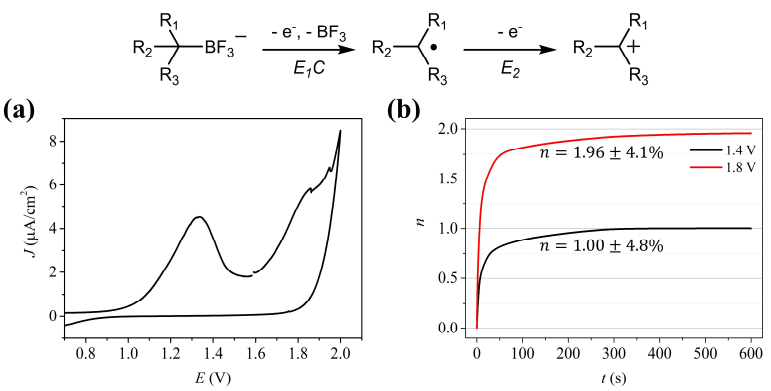

Figure 5. Electrochemical oxidation study of alkyltrifluoroborate salt using TEAM. (a) CV (10 mV/s) and (b) $n-t$ plots $\left(E_{\text {app }}=1.4\right.$ and $1.8 \mathrm{~V}$ ) of $1 \mathrm{mM}(4-\mathrm{MeOPh}) \mathrm{CHCH}_{3} \mathrm{BF}_{3} \mathrm{~K}$ in $0.1 \mathrm{M} \mathrm{TBAPF} 6$ of $\mathrm{MeCN}$ solution.

In addition to the nitrogen-centered electrochemistry of anilides, the TEAM was used to study organoboranes. The versatility of organoboranes provides access to valuable transformations in many fields of organic synthesis, ${ }^{41-46}$ with recent attention focused on photoredox ${ }^{42}$ and electrochemical reactions. ${ }^{41,46,47}$ Inagi et al. investigated the electrochemical oxidation of organoboranes in terms of oxidation potentials and studied oneelectron oxidation using voltammetric analysis and DFT calculations. ${ }^{41,45}$ In addition, the electrochemical generation of carbocations, implying two-electron transfer, has been recognized for only a few examples. ${ }^{41,47}$ However, the second oxidation process has not been characterized by electrochemical methods. Using the TEAM, the electrochemistry of an alkyltrifluoroborate salt, trifluoro(1-(4-methoxyphenyl)-ethyl)- $\lambda^{4}$-borane potassium salt ((4-MeOPh) $\left.\mathrm{CHCH}_{3} \mathrm{BF}_{3} \mathrm{~K}\right)$, was studied (Figure 5). The voltammogram showed two distinct peaks, each corresponding to SET, with a $\Delta E$ value of approximately $500 \mathrm{mV}$. The SET at $1.4 \mathrm{~V}$ is consistent with the wellknown mechanism for (photo)electrochemical radical generation. ${ }^{42,46,47}$ Moreover, the determination of an $n$ value of 2 at $1.8 \mathrm{~V}$ implies that the carbocation pathway could be enabled by manipulating the applied potentials.

In summary, we rediscovered thin-layer electrochemistry to develop a chip-type device, the TEAM, to clarify electrochemical reaction mechanisms. The thin-layer cell not only improved the resolution of the voltammetric peaks as compared to those obtained under semi-infinite diffusion conditions but also enabled the rapid and accurate determination of $n$ owing to the small analytical volume without lateral diffusion achieved using a polyelectrolyte gel. Using the TEAM, voltammetric/coulometric analyses and spectroelectrochemical studies were successfully conducted on well-known redox species and organic compounds that require mechanistic study, as summarized in Table S2. This work revealed the potential of the TEAM as a compact and easy-to-use device for exploring electron transfer steps in the fields of electroorganic/organometallic chemistry. We believe that the TEAM can contribute to organic electrosynthesis to gain insights for rational synthetic design without multistep screening or product analysis. Further developments will enable more complicated analyses of electrochemical reactions, such as investigating coupled chemical reactions or extracting kinetic parameters for electrochemical reactions.

\section{Supporting Information}


The Supporting Information is available free of charge online. Experimental details; additional simulation data and explanation; cross-sectional diagram of TEAM; synthetic scheme of pLA-TFPB, peak-to-peak separation of ferrocyanide CVs; $n-t$ plot without polyelectrolyte gel; CVs of Fc, FM1-43, and 4-MePhNHPiv with semi-infinite diffusion; summary of oxidation potential and $n$. (PDF)

Video of simulated concentration profile change in thin-layer cell. (Video S1)

\section{Corresponding Author}

*tdchung@snu.ac.kr

\section{Author Contributions}

SJS and JYK were responsible for the conceptualization, design and fabrication of the device, performing the experiments, data analysis and curation, and writing original draft and review and editing. These authors contributed equally. SA performed the electrochemical experiments and participated in discussion. MK set up the simulation with COMSOL and MATLAB. MS designed the device to realize the concept. SYG, HC and HGL synthesized and analyzed the alkyltrifluoroborate compound. MKL and MGK fabricated the device and performed electrochemical experiments. TDC was responsible for funding acquisition, writing and editing, supervision of the work.

\section{Notes}

The authors declare no competing financial interests.

\section{ACKNOWLEDGMENT}

This work was supported by the National Research Foundation of Korea(NRF) grant funded by the Korean government(MSIT) (No. 2021R1A5A1030054, 2017R1E1A1A01074236).

\section{REFERENCES}

(1) Hisatomi, T.; Domen, K. Reaction Systems for Solar Hydrogen Production via Water Splitting with Particulate Semiconductor Photocatalysts. Nat. Catal. 2019, 2 (5), 387-399.

https://doi.org/10.1038/s41929-019-0242-6.

(2) Nilges, P.; Schröder, U. Electrochemistry for Biofuel Generation: Production of Furans by Electrocatalytic Hydrogenation of Furfurals. Energy Environ. Sci. 2013, 6 (10), 2925-2931. https://doi.org/10.1039/c3ee41857j.

(3) Chadderdon, X. H.; Chadderdon, D. J.; Matthiesen, J. E.; Qiu, Y.; Carraher, J. M.; Tessonnier, J. P.; Li, W. Mechanisms of Furfural Reduction on Metal Electrodes: Distinguishing Pathways for Selective Hydrogenation of Bioderived Oxygenates. J. Am. Chem. Soc. 2017, 139 (40), 14120-14128. https://doi.org/10.1021/jacs.7b06331.

(4) Nielsen, D. U.; Hu, X. M.; Daasbjerg, K.; Skrydstrup, T. Chemically and Electrochemically Catalysed Conversion of $\mathrm{CO} 2$ to $\mathrm{CO}$ with Follow-up Utilization to Value-Added Chemicals. Nat. Catal. 2018, 1 (4), 244-254. https://doi.org/10.1038/s41929-018-0051-3.

(5) Lemaître, F.; Guille Collignon, M.; Amatore, C. Recent Advances in Electrochemical Detection of Exocytosis. Electrochim. Acta 2014, 140, 457-466. https://doi.org/10.1016/j.electacta.2014.02.059.

(6) Morofuji, T.; Shimizu, A.; Yoshida, J. Metal- and Chemical-Oxidant-Free C-H/C-H Cross-Coupling of 
Aromatic Compounds: The Use of Radical-Cation Pools. Angew. Chem. Int. Ed. 2012, 51 (29), 72597262. https://doi.org/10.1002/anie.201202788.

(7) Morofuji, T.; Shimizu, A.; Yoshida, J. Heterocyclization Approach for Electrooxidative Coupling of Functional Primary Alkylamines with Aromatics. J. Am. Chem. Soc. 2015, 137 (31), 9816-9819. https://doi.org/10.1021/jacs.5b06526.

(8) Waldvogel, S. R.; Mohle, S. Versatile Electrochemical C-H Amination via Zincke Intermediates. Angew. Chem. Int. Ed. 2015, 54 (22), 6398-6399. https://doi.org/10.1002/anie.201502638.

(9) Horn, E. J.; Rosen, B. R.; Chen, Y.; Tang, J.; Chen, K.; Eastgate, M. D.; Baran, P. S. Scalable and Sustainable Electrochemical Allylic C-H Oxidation. Nature 2016, 533 (7601), 77-81. https://doi.org/10.1038/nature17431.

(10) Fu, N.; Sauer, G. S.; Saha, A.; Loo, A.; Lin, S. Metal-Catalyzed Electrochemical Diazidation of Alkenes. Science 2017, 357 (6351), 575-579. https://doi.org/10.1126/science.aan6206.

(11) Kawamata, Y.; Yan, M.; Liu, Z.; Bao, D. H.; Chen, J.; Starr, J. T.; Baran, P. S. Scalable, Electrochemical Oxidation of Unactivated C-H Bonds. J. Am. Chem. Soc. 2017, 139 (22), 7448-7451.

https://doi.org/10.1021/jacs.7b03539.

(12) Sandford, C.; Edwards, M. A.; Klunder, K. J.; Hickey, D. P.; Li, M.; Barman, K.; Sigman, M. S.; White, H. S.; Minteer, S. D. A Synthetic Chemist's Guide to Electroanalytical Tools for Studying Reaction Mechanisms. Chem. Sci. 2019, 10 (26), 6404-6422. https://doi.org/10.1039/c9sc01545k.

(13) Wise, C. F.; Agarwal, R. G.; Mayer, J. M. Determining Proton-Coupled Standard Potentials and X-H Bond Dissociation Free Energies in Nonaqueous Solvents Using Open-Circuit Potential Measurements. J. Am. Chem. Soc. 2020, 142 (24), 10681-10691. https://doi.org/10.1021/jacs.0c01032.

(14) Costentin, C.; Savéant, J. M. Concepts and Tools for Mechanism and Selectivity Analysis in Synthetic Organic Electrochemistry. Proc. Natl. Acad. Sci. U. S. A. 2019, 166 (23), 11147-11152. https://doi.org/10.1073/pnas.1904439116.

(15) Saveant, J. M. Molecular Electrochemistry: Recent Trends and Upcoming Challenges. ChemElectroChem 2016, 3 (12), 1967-1977. https://doi.org/10.1002/celc.201600430.

(16) Peters, B. K.; Rodriguez, K. X.; Reisberg, S. H.; Beil, S. B.; Hickey, D. P.; Kawamata, Y.; Collins, M.; Starr, J.; Chen, L.; Udyavara, S.; Klunder, K.; Gorey, T. J.; Anderson, S. L.; Neurock, M.; Minteer, S. D.; Baran, P. S. Scalable and Safe Synthetic Organic Electroreduction Inspired by Li-Ion Battery Chemistry. Science 2019, 363 (6429), 838-845. https://doi.org/10.1126/science.aav5606.

(17) Hu, P.; Peters, B. K.; Malapit, C. A.; Vantourout, J. C.; Wang, P.; Li, J.; Mele, L.; Echeverria, P.-G.; Minteer, S. D.; Baran, P. S. Electroreductive Olefin-Ketone Coupling. J. Am. Chem. Soc. 2020, 142 (50), 20979-20986. https://doi.org/10.1021/jacs.0c11214.

(18) Mouahid, O. El; Coutanceau, C.; Belgsir, E. M.; Crouigneau, P.; Léger, J. M.; Lamy, C. Electrocatalytic Reduction of Dioxygen at Macrocycle Conducting Polymer Electrodes in Acid Media. J. Electroanal. Chem. 1997, 426 (1-2), 117-123. https://doi.org/10.1016/s0022-0728(96)04980-7.

(19) Baranski, A. S.; Fawcett, W. R.; Gilbert, C. M. Use of Microelectrodes for the Rapid Determination of the Number of Electrons Involved in an Electrode Reaction. Anal. Chem. 1985, 57 (1), 166-170. https://doi.org/10.1021/ac00279a041.

(20) Nishiumi, T.; Abdul, M. M.; Aoki, K. Determination of the Number of Electrons by 
Chronoamperometry at Small Electrodes. Electrochem. Commun. 2005, 7 (12), 1213-1217.

https://doi.org/10.1016/j.elecom.2005.08.030.

(21) Zhou, R.; Zheng, Y.; Jaroniec, M.; Qiao, S. Z. Determination of the Electron Transfer Number for the Oxygen Reduction Reaction: From Theory to Experiment. ACS Catal. 2016, 6 (7), 4720-4728. https://doi.org/10.1021/acscatal.6b01581.

(22) Treimer, S.; Tang, A.; Johnson, D. C. A Consideration of the Application of Koutecký-Levich Plots in the Diagnoses of Charge-Transfer Mechanisms at Rotated Disk Electrodes. Electroanalysis 2002, 14 (3), 165-171. https://doi.org/10.1002/1521-4109(200202)14:3<165::AID-ELAN165>3.0.CO;2-6.

(23) Hubbard, A. T.; Anson, F. C. Linear Potential Sweep Voltammetry in Thin Layers of Solution. Anal. Chem. 1966, 38 (1), 58-61. https://doi.org/10.1021/ac60233a015.

(24) Hubbard, A. T. Study of the Kinetics of Electrochemical Reactions by Thin-Layer Voltammetry. $J$. Electroanal. Chem. 1969, 22 (2), 165-174. https://doi.org/10.1016/s0022-0728(71)80210-3.

(25) Christensen, C. R.; Anson, F. C. Application of Thin Layer Chronopotentiometry to Kinetic Studies. Anal. Chem. 1964, 36 (3), 495-497. https://doi.org/10.1021/ac60209a052.

(26) Oglesby, D. M.; Omang, S. H.; Reilley, C. N. Thin Layer Electrochemical Studies Using Controlled Potential or Controlled Current. Anal. Chem. 1965, 37 (11), 1312-1316. https://doi.org/10.1021/ac60230a007.

(27) Kim, S. K.; Lim, H.; Chung, T. D.; Kim, H. C. A Miniaturized Electrochemical System with a Novel Polyelectrolyte Reference Electrode and Its Application to Thin Layer Electroanalysis. Sens. Actuators B 2006, 115 (1), 212-219. https://doi.org/10.1016/j.snb.2005.09.005.

(28) Ono, T.; Sugimoto, T.; Shinkai, S.; Sada, K. Lipophilic Polyelectrolyte Gels as Super-Absorbent Polymers for Nonpolar Organic Solvents. Nat. Mater. 2007, 6 (6), 429-433.

https://doi.org/10.1038/nmat1904.

(29) Sunaga, S.; Kokado, K.; Sada, K. Lipophilic Polyelectrolyte Gel Derived from Phosphonium Borate Can Absorb a Wide Range of Organic Solvents. Soft Matter 2018, 14 (4), 581-585. https://doi.org/10.1039/c7sm01841j.

(30) Deangelis, T. P.; Heineman, W. R. An Electrochemical Experiment Using an Optically Transparent Thin Layer Electrode. J. Chem. Educ. 1976, 53 (9), 594-597. https://doi.org/10.1021/ed053p594.

(31) Yu, J. S.; Yang, C.; Fang, H. Q. Variable Thickness Thin-Layer Cell for Electrochemistry and in Situ UV- VIS Absorption, Luminescence and Surface-Enhanced Raman Spectroelectrochemistry. Anal. Chim. Acta 2000, 420 (1), 45-55. https://doi.org/10.1016/S0003-2670(00)01005-9.

(32) Tsierkezos, N. G.; Ritter, U. Electrochemical Impedance Spectroscopy and Cyclic Voltammetry of Ferrocene in Acetonitrile/Acetone System. J. Appl. Electrochem. 2010, 40 (2), 409-417. https://doi.org/10.1007/s10800-009-0011-3.

(33) Cochilla, A. J.; Angleson, J. K.; Betz, W. J. Monitoring Secretory Membrane With Fm1-43 Fluorescence. Annu. Rev. Neurosci. 2002, 22 (1), 1-10. https://doi.org/10.1146/annurev.neuro.22.1.1.

(34) Kutterer, K. M. K.; Davis, J. M.; Singh, G.; Yang, Y.; Hu, W.; Severin, A.; Rasmussen, B. A.; Krishnamurthy, G.; Failli, A.; Katz, A. H. 4-Alkyl and 4,4'-Dialkyl 1,2-Bis(4Chlorophenyl)Pyrazolidine-3,5-Dione Derivatives as New Inhibitors of Bacterial Cell Wall Biosynthesis. Bioorg. Med. Chem. Lett. 2005, 15 (10), 2527-2531. 
https://doi.org/https://doi.org/10.1016/j.bmcl.2005.03.058.

(35) Gilbert, A. M.; Failli, A.; Shumsky, J.; Yang, Y.; Severin, A.; Singh, G.; Hu, W.; Keeney, D.; Petersen, P. J.; Katz, A. H. Pyrazolidine-3,5-Diones and 5-Hydroxy-1H-Pyrazol-3(2H)-Ones, Inhibitors of UDP-NAcetylenolpyruvyl Glucosamine Reductase. J. Med. Chem. 2006, 49 (20), 6027-6036. https://doi.org/10.1021/jm060499t.

(36) Deng, G.; Li, W.; Shen, J.; Jiang, H.; Chen, K.; Liu, H. Pyrazolidine-3,5-Dione Derivatives as Potent Non-Steroidal Agonists of Farnesoid X Receptor: Virtual Screening, Synthesis, and Biological Evaluation. Bioorg. Med. Chem. Lett. 2008, 18 (20), 5497-5502. https://doi.org/https://doi.org/10.1016/j.bmcl.2008.09.027.

(37) Nishiu, J.; Ito, M.; Ishida, Y.; Kakutani, M.; Shibata, T.; Matsushita, M.; Shindo, M. JTP-426467 Acts as a Selective Antagonist for Peroxisome Proliferator-Activated Receptor $\Gamma$ in Vitro and in Vivo. Diabetes, Obes. Metab. 2006, 8 (5), 508-516. https://doi.org/https://doi.org/10.1111/j.1463-1326.2005.00536.x.

(38) Zhang, X.-Y.; Gu, Y.-F.; Chen, T.; Yang, D.-X.; Wang, X.-X.; Jiang, B.-L.; Shao, K.-P.; Zhao, W.; Wang, C.; Wang, J.-W.; Zhang, Q.-R.; Liu, H.-M. Synthesis, in Vitro and in Vivo Anticancer Activities of Novel 4-Substituted 1,2-Bis(4-Chlorophenyl)-Pyrazolidine-3,5-Dione Derivatives. Med. Chem. Commun. 2015, 6 (10), 1781-1786. https://doi.org/10.1039/C5MD00240K.

(39) Aiba née Kaneko, M.; Hirota, M.; Kouzuki, H.; Mori, M. Prediction of Genotoxic Potential of Cosmetic Ingredients by an in Silico Battery System Consisting of a Combination of an Expert Rule-Based System and a Statistics-Based System. J. Toxicol. Sci. 2015, 40 (1), 77-98. https://doi.org/10.2131/jts.40.77.

(40) Gieshoff, T.; Kehl, A.; Schollmeyer, D.; Moeller, K. D.; Waldvogel, S. R. Insights into the Mechanism of Anodic N-N Bond Formation by Dehydrogenative Coupling. J. Am. Chem. Soc. 2017, 139 (35), 12317-12324. https://doi.org/10.1021/jacs.7b07488.

(41) Suzuki, J.; Tanigawa, M.; Inagi, S.; Fuchigami, T. Electrochemical Oxidation of Organotrifluoroborate Compounds. ChemElectroChem 2016, 3 (12), 2078-2083. https://doi.org/10.1002/celc.201600451.

(42) Yan, H.; Hou, Z. W.; Xu, H. C. Photoelectrochemical C-H Alkylation of Heteroarenes with Organotrifluoroborates. Angew. Chem. Int. Ed. 2019, 58 (14), 4592-4595. https://doi.org/10.1002/anie.201814488.

(43) Kaur, P.; Khatik, G. L.; Nayak, S. K. A Review on Advances in Organoborane-Chemistry: Versatile Tool in Asymmetric Synthesis. Curr. Org. Synth. 2016, 14 (5), 665-682. https://doi.org/10.2174/1570179414666161104162038.

(44) Fyfe, J. W. B.; Watson, A. J. B. Recent Developments in Organoboron Chemistry: Old Dogs, New Tricks. Chem 2017, 3 (1), 31-55. https://doi.org/10.1016/j.chempr.2017.05.008.

(45) Inagi, S.; Fuchigami, T. Electrochemical Properties and Reactions of Organoboron Compounds. Curr. Opin. Electrochem. 2017, 2 (1), 32-37. https://doi.org/10.1016/j.coelec.2017.02.007.

(46) Luo, J.; Hu, B.; Wu, W.; Hu, M.; Liu, T. L. Nickel-Catalyzed Electrochemical C( $\left(\mathrm{sp}^{3}\right)-\mathrm{C}\left(\mathrm{sp}^{2}\right)$ CrossCoupling Reactions of Benzyl Trifluoroborate and Organic Halides. Angew. Chem. Int. Ed. 2021, 60 (11), 6107-6116. 
https://doi.org/10.1002/anie.202014244.

(47) Inagi, S.; Fuchigami, T. Electrochemical Properties and Reactions of Organoboron Compounds. Curr. Opin. Electrochem. 2017, 2 (1), 32-37.

https://doi.org/10.1016/j.coelec.2017.02.007. 